\title{
Identification of serum anti-striatin 4 antibodies as a common marker for esophageal cancer and other solid cancers
}

\author{
MASAAKI ITO $^{1}$, TAKAKI HIWASA ${ }^{1,2}$, YOKO OSHIMA ${ }^{3}$, SATOSHI YAJIMA $^{3}$, TAKASHI SUZUKI ${ }^{3}$, \\ TATSUKI NANAMI $^{3}$, MAKOTO SUMAZAKI ${ }^{3}$, FUMIAKI SHIRATORI ${ }^{3}$, KIMIHIKO FUNAHASHI ${ }^{3}$, \\ HIROTAKA TAKIZAWA ${ }^{4}$, KOICHI KASHIWADO ${ }^{5}$, NAOBUMI TOCHIGI ${ }^{6}$ and HIDEAKI SHIMADA ${ }^{1,3}$ \\ ${ }^{1}$ Department of Clinical Oncology, Toho University Graduate School of Medicine, Ota-ku, Tokyo 143-8541; \\ ${ }^{2}$ Department of Neurological Surgery, Chiba University Graduate School of Medicine, Chuo-ku, Chiba 260-8670; \\ ${ }^{3}$ Department of Gastroenterological Surgery, Toho University School of Medicine, Ota-ku, Tokyo 143-8541; \\ ${ }^{4}$ Port Square Kashiwado Clinic, Kashiwado Memorial Foundation, Chuo-ku, Chiba 260-0025; \\ ${ }^{5}$ Department of Neurology, Kashiwado Hospital, Chuo-ku, Chiba 260-0854; \\ ${ }^{6}$ Department of Surgical Pathology, Toho University School of Medicine, Ota-ku, Tokyo 143-8541, Japan
}

Received August 5, 2020; Accepted July 21, 2021

DOI: $10.3892 / \mathrm{mco} .2021 .2399$

\begin{abstract}
Solid cancers have a poor prognosis, and their morbidity and mortality after surgery is high. Even after radical surgery for esophageal cancer, there have been cases of early postoperative death. The present study therefore aimed to explore new tumor markers that can predict the early postoperative prognosis. To identify antibody markers, serological antigens were identified using recombinant cDNA expression cloning (SEREX). The results identified striatin 4 (STRN4) as the antigen recognized by serum IgG antibodies in patients with esophageal cancer. After performing an amplified luminescence proximity homogeneous assay-linked immunosorbent assay (AlphaLISA), it was revealed that when compared with healthy donors, serum anti-STRN4 antibody (STRN4-Ab) levels were significantly higher not only in patients with esophageal cancer but also to lesser extent, in those with gastric cancer, colorectal cancer, lung cancer and breast cancer. Compared with STRN4-Ab-negative patients with esophageal cancer, STRN4-Ab-positive patients had a poorer postoperative prognosis at early stages, suggesting that STRN4-Abs may be useful for predicting poor early-stage prognoses of patients with esophageal cancer. The positive diagnosis rates of esophageal cancer using the STRN4-Ab marker and conventional markers, including squamous cell carcinoma antigen and p53 antibody alone, were 26.4, 35.2 and $19.1 \%$ respectively; a result that increased up to
\end{abstract}

Correspondence to: Dr Hideaki Shimada, Department of Gastroenterological Surgery, Toho University School of Medicine, 6-11-1 Omori-Nishi, Ota-ku, Tokyo 143-8541, Japan

E-mail: hideaki.shimada@med.toho-u.ac.jp

Key words: serum anti-striatin 4 antibody, esophageal cancer, biomarker, overall survival
$59.1 \%$ by combining all three markers. Serum STRN4-Ab may serve as a novel marker of esophageal cancer.

\section{Introduction}

Esophageal cancer has malignant potential and often results in early recurrence and a poor prognosis (1). Squamous cell carcinoma antigen (SCC-Ag), cytokeratin 19 fragment (CYFRA), and carcinoembryonic antigen (CEA) have been employed as biomarkers for esophageal cancer. MicroRNA and serological markers have been reported as new biomarkers, but the results have been unsatisfactory $(2,3)$. The serum anti-p53 antibody test has recently been developed and has been employed worldwide to detect superficial esophageal SCC $(4,5)$. The positive rate of serum anti-p53 was $30 \%$ (6); however, there are few biomarkers that have shown such high sensitivity and specificity (7-10). New biomarkers that can estimate the short-term postoperative prognosis are effective because they can help physicians select the appropriate postoperative adjuvant therapy during the early postoperative period.

Serological identification of antigens by recombinant cDNA expression cloning (SEREX) is an effective screening method for tumor markers (11). SEREX involves the immune-screening of cDNA libraries prepared from tumor specimens from patients' sera. The sequencing of isolated cDNA clones makes SEREX suitable for the large-scale screening of tumor antigens. SEREX has been applied to various human tumor types and has identified more than 1000 novel tumor antigens (SEREX antigens) (12).

We conducted a large-scale SEREX screening using sera from patients with esophageal cancer and identified TROP2/TACSTD2 (13), SLC2A1/GLUT1 (14), tripartite motif-containing 21 (15), myomegalin (16), makorin 1 (17) and esophageal carcinoma SEREX antigen (ECSA) (18). In the present study, we further identified striatin 4 (STRN4) as a novel esophageal SEREX antigen and evaluated 
clinicopathological significance of serum anti-STRN4 antibody (s-STRN4-Ab) levels in patients with solid tumors.

\section{Materials and methods}

Collection of serum samples. The study was approved by the Ethics Committee of Toho University, Graduate School of Medicine (no. A18103) and Chiba University Graduate School of Medicine (no. 2018-320) (Japan). We collected sera from patients who had provided written informed consent.

Serum samples were obtained from 672 patients, including 192 with esophageal cancer, 96 with gastric cancer, 192 with colorectal cancer, 96 with lung cancer, and 96 with breast cancer from Toho University Omori Hospital (Japan) between June 2010 and February 2016. Among the 192 patients with esophageal cancer, 91 underwent radical surgery. Among them, 63 patients underwent neoadjuvant chemotherapy. The number of patients in each stage for esophageal cancer (Japanese Classification of Esophageal Cancer, 11th Edition (19) was as follows: 9 patients in stage 0,14 in stage I, 25 in stage II, 34 in stage III, and 9 in stage IVa. Gastric cancer was analyzed in 57 cases and colorectal cancer was analyzed in 113 cases, of which all cases were underwent radical surgery. Excluded cases were those with double cancer and pathologically difficult staging due to neoadjuvant chemotherapy. The number of patients in each stage for gastric cancer (Japanese classification of gastric carcinoma: 3rd English edition (20) was as follows: 28 patients in stage I, 14 in stage II, 8 in stage III, and 7 in stage IV. And the number of patients for colorectal cancer (Japanese Classification of Colorectal, Appendiceal, and Anal Carcinoma: the 3d English Edition [Secondary Publication] (21) was as follows: 5 patients in stage 0,29 in stage I, 32 in stage II, 31 in stage III, and 16 in stage IV.

All patients were regularly followed-up until July 2018 or death. Healthy donor sera were obtained from Port Square Kashiwado Clinic.

SEREX screening. SEREX screening was performed using sera from patients with esophageal cancer as previously described (13-18). The isolated STRN4 cDNA was recombined into the EcoRI/XhoI site of pGEX-4T-3 (GE Healthcare Life Sciences,Pittsburgh,PA).Expression of STRN4-GST or control GST was induced by treating pGEX-4T-3-STRN4-transformed or control pGEX-4T-3-transformed Escherichia coli (E. coli) BL21 with 0.1-mM isopropyl- $\beta$-D-thiogalactoside (IPTG) at $37^{\circ} \mathrm{C}$ for $3 \mathrm{~h}$. The cells were subsequently lysed in BugBuster Master Mix (Merck Millipore, Darmstadt, Germany). STRN4-GST and GST proteins were purified by glutathione-Sepharose (GE Healthcare Life Sciences) column chromatography according to the manufacturer's instructions as previously described (22-26).

Serum sampling and AlphaLISA for serum markers. Serum samples were collected prior to treatment and were kept frozen at $-80^{\circ} \mathrm{C}$ until use. s-STRN4-Ab levels were examined using amplified luminescence proximity homogeneous assay-linked immunosorbent assay (AlphaLISA), which was performed using 384-well microtiter plates (white opaque OptiPlate ${ }^{\mathrm{TM}}$; Perkin Elmer) containing $2.5 \mu \mathrm{l}$ of 1/100-diluted sera and $2.5 \mu 1$ of GST or GST-fusion STRN4 protein $(10 \mu \mathrm{g} / \mathrm{ml})$ in AlphaLISA buffer $(25 \mathrm{mM}$ HEPES, pH 7.4, $0.1 \%$ casein, $0.5 \%$ Triton X-100, $1-\mathrm{mg} / \mathrm{ml}$ dextran-500, and $0.05 \%$ Proclin-300) according to the manufacturer's instructions (Perkin Elmer, http://www.perkinelmer. com/lab-solutions/resources/docs/GDE_ELISA-to-AlphaLISA. pdf). The reaction mixture was incubated at room temperature for 6-8 h. Next, anti-human IgG-conjugated acceptor beads ( $2.5 \mu \mathrm{l}$ of $40 \mu \mathrm{g} / \mathrm{ml})$ and glutathione-conjugated donor beads $(2.5 \mu \mathrm{l}$ of $40 \mu \mathrm{g} / \mathrm{ml})$ were added and incubated further for 14 days at room temperature in the dark. The chemical emission was measured by an EnSpire Alpha microplate reader (PerkinElmer) as previously described (27-29). Specific reactions were calculated by subtracting the Alpha values of the GST control from the GST-STRN4 values. The serum p-53 antibodies (p53-Abs) (30) and SCC-Ag (31) were also evaluated as previously described. Cutoff values for serum p53-Abs and SCC-Ag were fixed at $1.3 \mathrm{IU} / \mathrm{ml}$ and $1.5 \mathrm{ng} / \mathrm{ml}$, respectively.

Statistical analysis. The continuous data are expressed as mean \pm standard deviation. Receiver operating characteristic curve analysis was a typical method to determine the sensitivity and specificity from the serum STRN4-Ab (s-STRN4-Ab) level between healthy donor and cancer patients to set at the values that maximize the sums of the sensitivity and specificity. Area under the curve (AUC) was defined by the area of under the curve of the ROC curve. The closer the AUC is to 1 , it is judged that the discrimination performance is high. Comparisons between unpaired groups were conducted using the Mann-Whitney U test. Differences in the distribution of two variables were evaluated using Fisher's exact test or the chi-squared test. The corresponding differences among three variables were evaluated with the Kruskal-Wallis test. We analyzed the clinicopathological data using logistic regression analysis to evaluate the association with s-STRN4-Ab level. We calculated the survival curves using the Kaplan-Meier method and compared them using the log-rank test. All analyses were performed using EZR software (32), and statistical significance levels were defined as $\mathrm{P}<0.05$.

\section{Results}

Comparison of s-STRN4-Ab levels between healthy donors and patients with solid tumors. SEREX screening identified striatin 4 (STRN4; accession number: NM_013403) as an antigen recognized by serum IgG antibodies in patients with esophageal cancer. We then recombined the cDNA, purified the STRN4-GST protein and examined the s-STRN4-Ab levels in patients with esophageal cancer, gastric cancer, colorectal cancer, lung cancer, and breast cancer. The mean s-STRN4-Ab levels ( \pm standard deviation) were as follows: healthy donors, $777 \pm 2308$; esophageal cancer, $2878 \pm 5846$; gastric cancer, 2605 \pm 6440 ; colorectal cancer, $2531 \pm 7545$; lung cancer, 2977 \pm 7537 ; and breast cancer, $1616 \pm 3535$. Compared with the healthy donors, the patients with any type of cancer showed significantly higher levels of s-STRN4-Abs in the Kruskal-Wallis test (Fig. 1), suggesting that s-STRN4-Ab is a common marker for solid cancers. The levels were especially higher for esophageal cancer and lung cancer but relatively lower for breast cancer. 


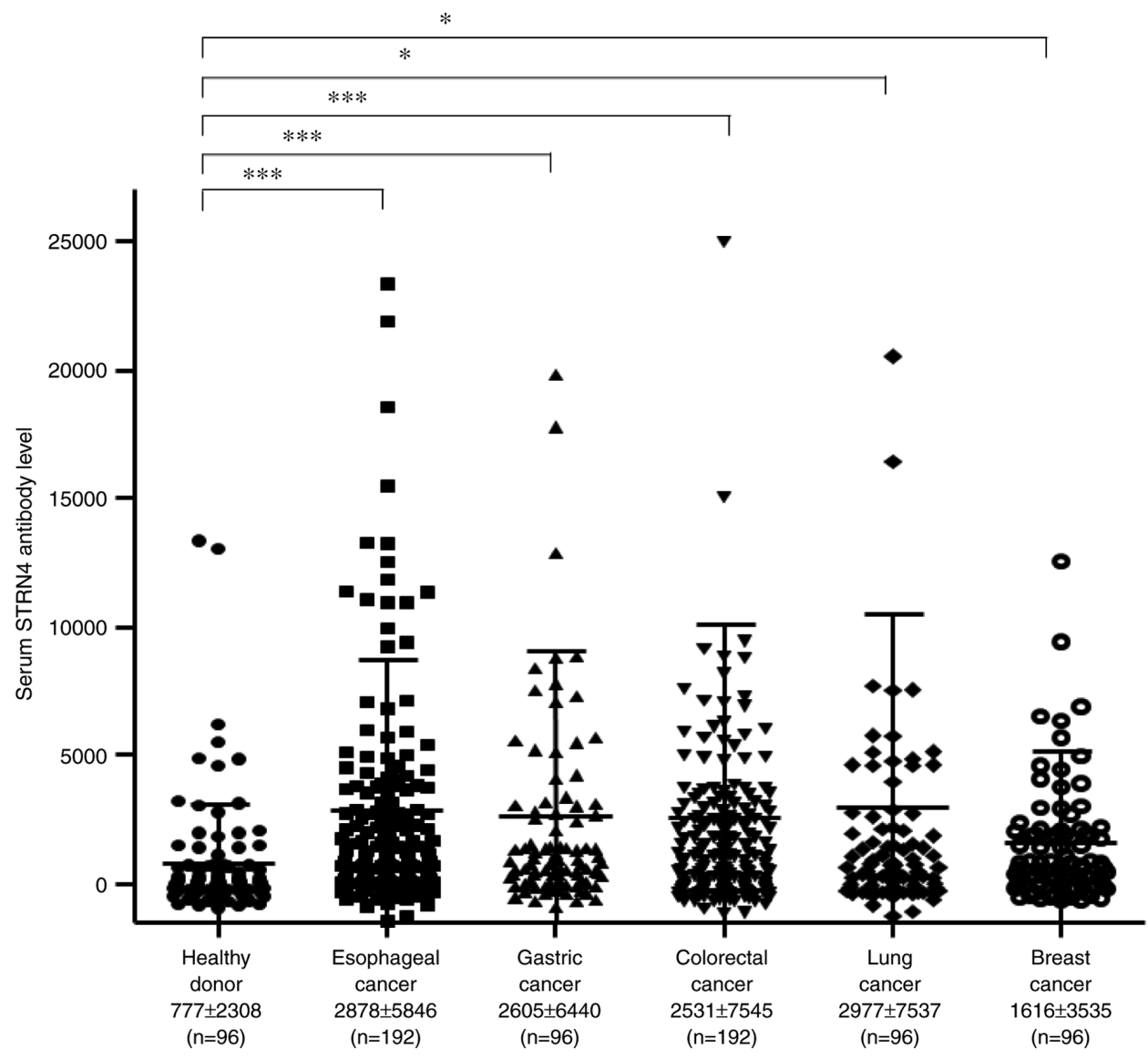

Figure 1. Comparison of serum anti-STRN4 antibody levels between solid cancers and healthy donors. Levels of serum STRN4 antibodies in healthy donors and patients with esophageal cancer, gastric cancer, colorectal cancer, lung cancer and breast cancer were examined by an amplified luminescence proximity homogeneous assay-linked immunosorbent assay. Data are presented as the mean \pm SD. ${ }^{*} \mathrm{P}<0.05$ and ${ }^{* * *} \mathrm{P}<0.001$. STRN4, striatin 4.

We then performed a receiver operating characteristic curve analysis to evaluate the sensitivity and specificity between each cancer and the healthy donors (Fig. 2). The results revealed that the AUC values were $>0.6$ for all cancers (Table I). When the cutoff value was set at the values that maximize the sums of the sensitivity and specificity, the sensitivity and specificity of s-STRN4-Abs for esophageal cancer were 67.2 and $67.7 \%$, respectively.

Comparison of $s$-STRN4-Ab levels according to various laboratory data. Given that the AUC was the highest for esophageal cancer among the solid cancers (Table I), we focused on 91 surgical cases of esophageal cancer and examined their clinicopathological features. The mean ( \pm standard deviation (SD)) s-STRN4-Ab levels for stage 0 , stage I, stage II, stage III, and stage IVa were $718 \pm 1351$, $1371 \pm 1727,1935 \pm 2368,1087 \pm 1537$ and $2121 \pm 1772$, respectively (Fig. 3A). In the gastric cancer, the mean \pm SD of s-STRN4-Ab levels for stage I, stage II, stage III, and stage IV were $2336 \pm 3007,2749 \pm 3539,3455 \pm 4343$, and $2101 \pm 2473$, respectively (Fig. 3B). In the colorectal cancer, the mean \pm SD s-STRN4-Ab levels for stage 0, stage I, stage II, stage III, and stage IV were $3666 \pm 3689,1855 \pm 2705$, $1385 \pm 2368,1169 \pm 1978$, and $1970 \pm 1813$, respectively (Fig. 3C). Although there was no significant association between each stage and a s-STRN4 antibody level in the Kruskal-Wallis test in all three cancers, the mean STRN4 levels for stages I, II, III, and IV were higher than for stage 0 in terms of esophageal cancer.

Relationship between s-STRN4-Ab levels and overall survival. We then divided the s-STRN4-Ab levels for esophageal cancer into quartiles (Q1, Q2, Q3 and Q4). The s-STRN4-Ab levels ranged from -827 to 184 for Q1, 190 to 873 for Q2, 1106 to 2746 for Q3 and 2876 to 39727 for Q4. Although there were no significant differences in overall survival between the Q1+Q2+Q3 and $\mathrm{Q} 4$ groups ( $\mathrm{P}=0.508), \mathrm{Q} 4$ group showed poor prognosis at early stage (10-36 weeks) after surgery. (Fig. 4A). In terms of gastric and colorectal cancer, there was no statistically significant correlation between Q1+Q2+Q3 vs. Q4 groups (Fig. 4B and C).

Relationship between high serum STRN4 antibody levels and clinicopathological factors. The univariate and multivariate analysis showed no significant association for esophageal cancer between s-STRN4-Ab levels and sex, age, tumor depth, lymph node status, location, white blood cell count, neutrophil count, lymphocyte count, hemoglobin count, platelet count, C-reactive protein level, albumin level, SCC-Ag level, and p53-Abs (Tables II and III). In terms of gastric and colorectal cancer, there was no significant association for clinicopathological factors (data not shown).

Combination assessment of $s$-STRN4-Ab and conventional tumor markers. To evaluate the usefulness of s-STRN4-Ab 
Table I. Comparison of AUC, 95\% confidence intervals, cutoff levels, sensitivity, specificity and P-values from patients with various cancer types.

\begin{tabular}{lccccc}
\hline Variable & $\begin{array}{c}\text { Esophageal } \\
\text { cancer }\end{array}$ & $\begin{array}{c}\text { Gastric } \\
\text { cancer }\end{array}$ & $\begin{array}{c}\text { Colorectal } \\
\text { cancer }\end{array}$ & $\begin{array}{c}\text { Lung } \\
\text { cancer }\end{array}$ & $\begin{array}{c}\text { Breast } \\
\text { cancer }\end{array}$ \\
\hline AUC & 0.694 & 0.682 & 0.653 & 0.616 & 0.639 \\
$95 \%$ CI & $0.630-0.758$ & $0.606-0.758$ & $0.587-0.718$ & $0.536-0.696$ & $0.560-0.718$ \\
Cutoff & $>329.0$ & $>365.0$ & $>785.0$ & $>321.0$ & $>208.0$ \\
Sensitivity (\%) & 67.2 & 70.8 & 53.6 & 56.2 & 65.6 \\
Specificity $(\%)$ & 67.7 & 67.7 & 79.2 & 67.7 & 61.5 \\
P-value & $<0.001$ & $<0.001$ & $<0.001$ & $<0.001$ & $<0.001$ \\
\hline
\end{tabular}

AUC, area under the curve; CI, confidence interval.
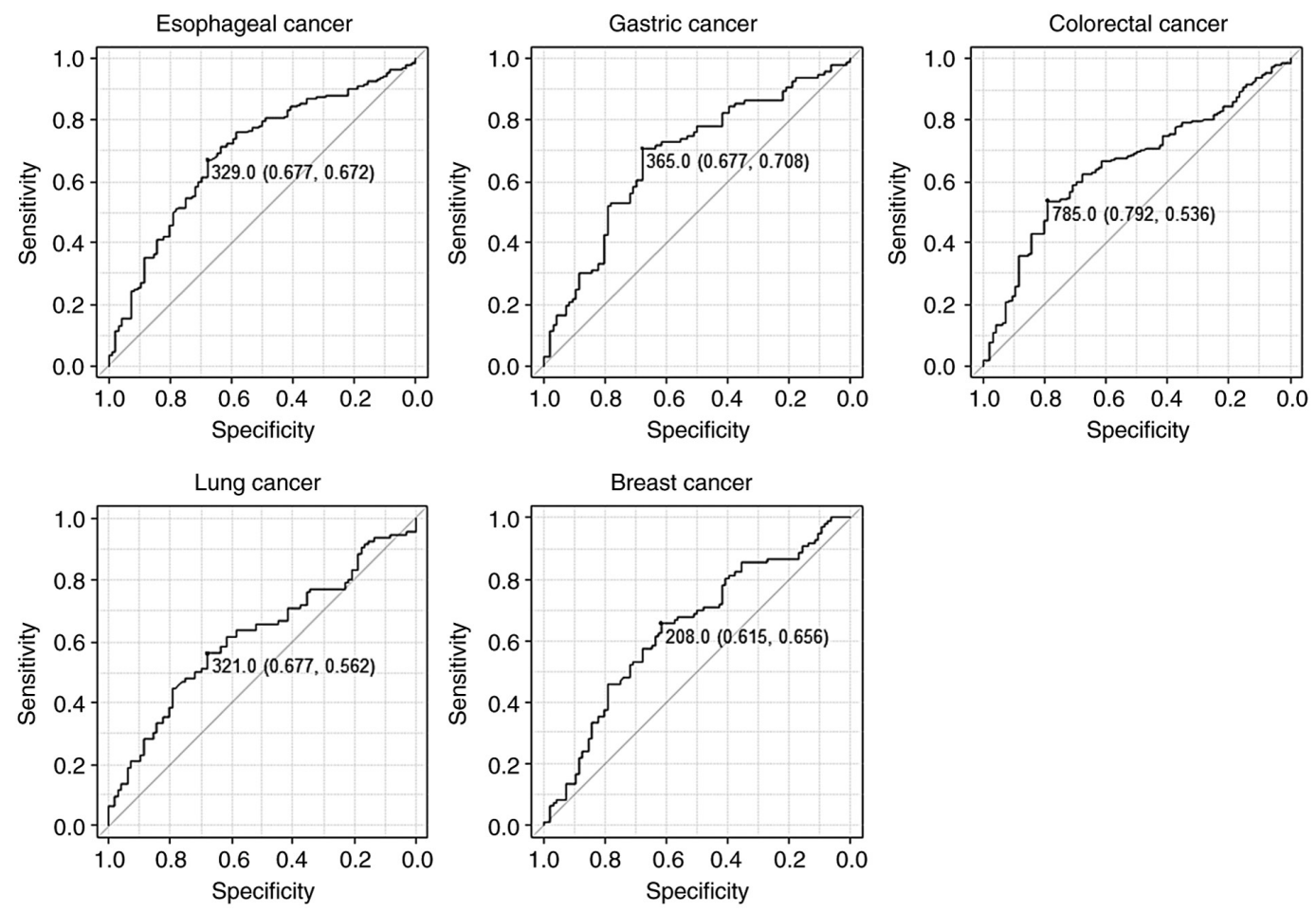

Figure 2. Receiver operating characteristic curve analysis was performed to evaluate the sensitivity and specificity of each cancer type and healthy donor assessed. Numbers in the figure represent cutoff level, specificity and sensitivity.

for esophageal cancer, we compared it with the conventional tumor markers, SCC-Ag and p53-Abs. When we decided the s-STRN4-Ab cutoff level at 2746 (the border between Q3 and Q4), the positive rate was $26.4 \%$, which was comparable to $19.1 \%$ for p53-Ab and $35.2 \%$ for SCC-Ag (Fig. 5). We then examined the positive rates of s-STRN4-Ab combined with the conventional tumor markers. The positive rates for SCC-Ag plus s-STRN4-Ab, p53-Ab plus s-STRN4-Ab, and SCC-Ag plus p53-Abs were 49.4, 40.4, and 48.3\%, respectively. By combining all of the markers, the positivity increased to $59.1 \%$. Thus, addition of s-STRN4-Ab marker improved the sensitivity.

\section{Discussion}

We found that s-STRN4-Ab levels were significantly higher in the solid cancer group (esophageal cancer, gastric cancer, colorectal cancer, lung cancer, and breast cancer) than the healthy donor group. P-values of digestive organ cancers vs. HD were much lower $(<0.001)$ than that of lung cancer $(<0.05)$. Given that the AUC value for esophageal cancer was highest among all examined AUC values, we focused on esophageal cancer and evaluated its clinicopathological character and prognosis; however, there were no statistically significant correlation between s-STRN4-Ab and clinicopathological character including TNM. In the stage-by-stage analysis, however, s-STRN4-Ab levels at stages II, III and IV were higher than at stage 0 . There was no correlation between STRN4 and other tumor markers in the univariate and multivariate analysis, indicating that the positive rate increased by the combined diagnosis of these markers.

STRN, STRN3 and STRN4 are members of the striatin family of proteins that contain multiple 
Table II. Fisher's exact comparison of serum levels according to the clinicopathological characteristics of patients with esophageal cancer.

\begin{tabular}{|c|c|c|c|}
\hline Variables & $\begin{array}{c}\text { STRN4 } \\
\text { Q1+Q2+Q3 }\end{array}$ & $\begin{array}{l}\text { STRN4 } \\
\text { Q4 }\end{array}$ & P-value \\
\hline Sex & & & $>0.999$ \\
\hline Male & 51 & 19 & \\
\hline Female & 16 & 5 & \\
\hline Age & & & 0.810 \\
\hline$>65$ & 38 & 15 & \\
\hline$\leq 65$ & 29 & 9 & \\
\hline Location & & & 0.753 \\
\hline Upper & 11 & 3 & \\
\hline Lower & 56 & 21 & \\
\hline Tumor depth & & & 0.454 \\
\hline $\mathrm{T} 1$ & 23 & 6 & \\
\hline $\mathrm{T} 2-\mathrm{T} 4$ & 44 & 18 & \\
\hline Lymph node status & & & 0.636 \\
\hline N0 & 29 & 12 & \\
\hline N1 & 38 & 12 & \\
\hline WBC $(\mu 1)$ & & & $>0.999$ \\
\hline$>8,000$ & 8 & 3 & \\
\hline$\leq 8,000$ & 59 & 21 & \\
\hline Neutrophil (\%) & 15 & 4 & 0.771 \\
\hline$>70$ & 15 & 4 & \\
\hline$\leq 70$ & 52 & 20 & \\
\hline Lymphocyte (\%) & & & 0.371 \\
\hline$>35$ & 11 & 6 & \\
\hline$\leq 35$ & 56 & 18 & \\
\hline Hemoglobin (g/dl) & & & 0.450 \\
\hline$>12$ & 43 & 18 & \\
\hline$\leq 12$ & 24 & 6 & \\
\hline Platelet & & & 0.375 \\
\hline$>150,000$ & 63 & 21 & \\
\hline$\leq 150,000$ & 4 & 3 & \\
\hline $\operatorname{CRP}(\mathrm{mg} / \mathrm{dl})^{\mathrm{a}}$ & & & 0.450 \\
\hline$>0.3$ & 20 & 9 & \\
\hline$\leq 0.3$ & 46 & 14 & \\
\hline Albumin (g/dl) & & & 0.596 \\
\hline$>3.5$ & 51 & 17 & \\
\hline$\leq 3.5$ & 16 & 7 & \\
\hline SCC-Ag $(\mathrm{ng} / \mathrm{ml})^{\mathrm{a}}$ & & & 0.447 \\
\hline$>1.5$ & 21 & 10 & \\
\hline$\leq 1.5$ & 44 & 13 & \\
\hline p53-Abs $(\mathrm{U} / \mathrm{ml})^{\mathrm{a}}$ & & & 0.770 \\
\hline$>1.30$ & 12 & 5 & \\
\hline$\leq 1.30$ & 53 & 19 & \\
\hline
\end{tabular}

${ }^{\text {a}}$ Data represents a loss value. N0, no lymph node metastasis; N1, lymph node metastasis; WBC, white blood cell; CRP, C-reactive protein; SCC-Ag, squamous cell carcinoma antigen; Abs, antibodies; STRN4, striatin 4; Q, quartiles of serum STRN4 antibody levels.

protein-binding domains including the coiled-coil domain, $\mathrm{Ca}^{2+}$-calmodulin-binding domain, caveolin-binding domain, and WD-repeat domain (33-35). Striatin family proteins are also known to form a complex with protein phosphatases and protein kinases, which further regulates the signaling pathways involved in cell proliferation, differentiation, apoptosis, and transformation $(36,37)$. These results indicate that STRN4 is involved in the early stage of carcinogenesis. It has also been 
Table III. Logistic regression analysis of serum levels according to the clinicopathological characteristics of patients with esophageal cancer.

\begin{tabular}{lccc}
\hline Variable & Odds ratio & $95 \%$ CI & P-value \\
\hline Tumor depth & 1.890 & $0.545-6.570$ & 0.315 \\
Lymphocyte (\%) & 2.260 & $0.643-7.920$ & 0.204 \\
Hemoglobin (g/dl) & 0.417 & $0.130-1.340$ & 0.141 \\
Platelet & 2.240 & $0.436-11.50$ & 0.333 \\
SCC-Ag $^{\mathrm{a}}$ & 1.540 & $0.522-4.520$ & 0.436 \\
\hline
\end{tabular}

${ }^{\text {aD }}$ ata represents a loss value. CI, confidence interval; SCC-Ag, squamous cell carcinoma antigen.
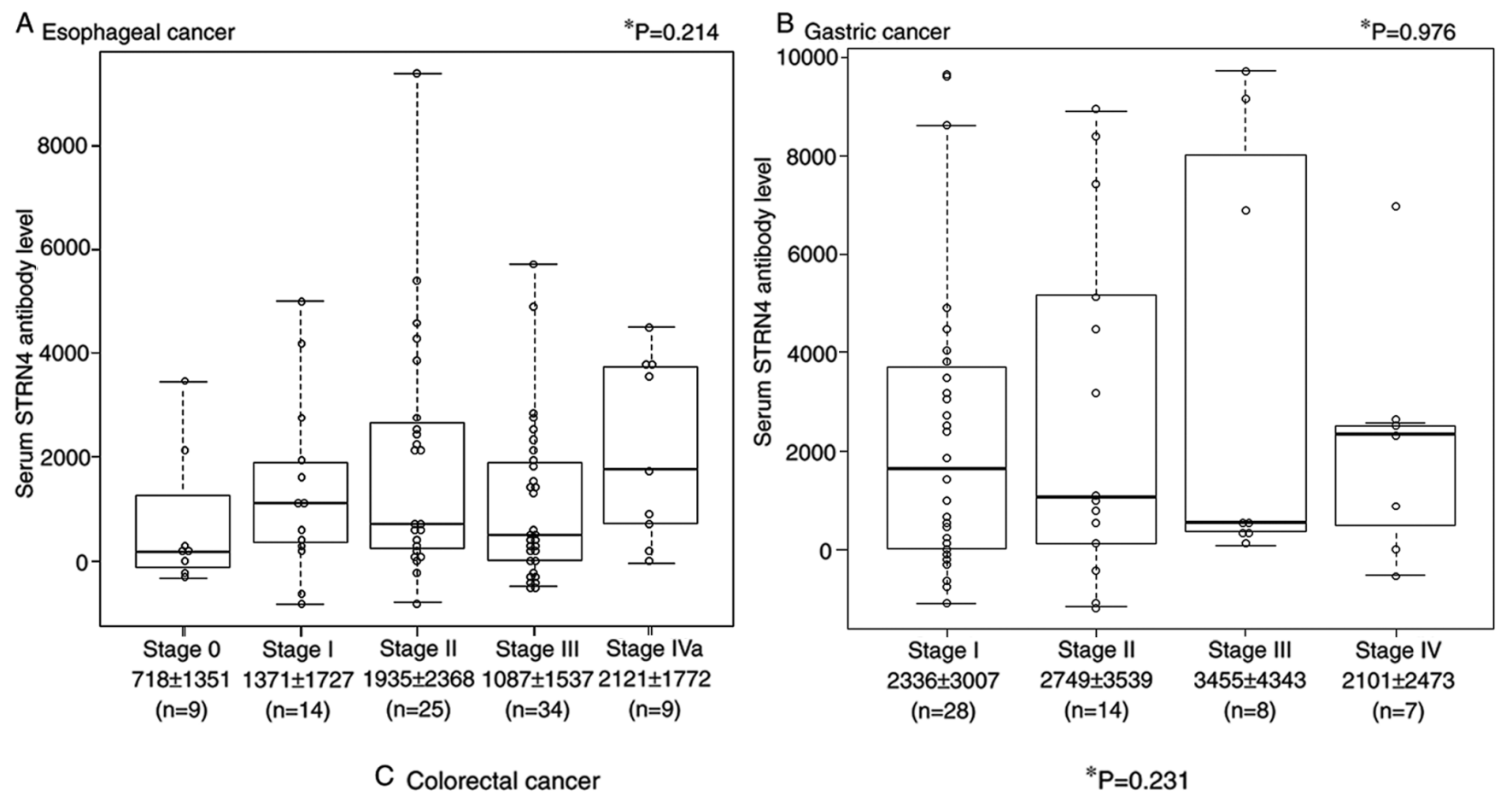

C Colorectal cancer
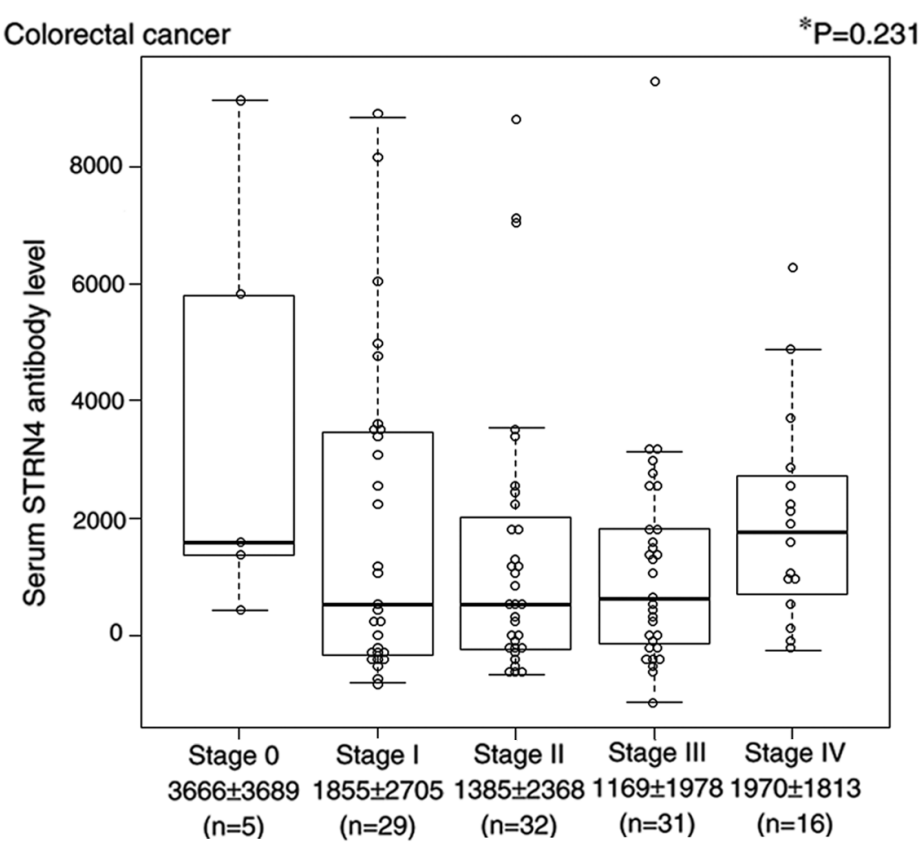

Figure 3. Serum STRN4 antibody levels divided according to each stage of (A) esophageal cancer, (B) gastric cancer and (C) colorectal cancer. The box plot represents 25,50 and 75 percentiles. The upper and lower horizontal lines represent the limits. There was no statistically significant difference between stages "P-value as indicated. STRN4, striatin 4. 
A Esophageal cancer

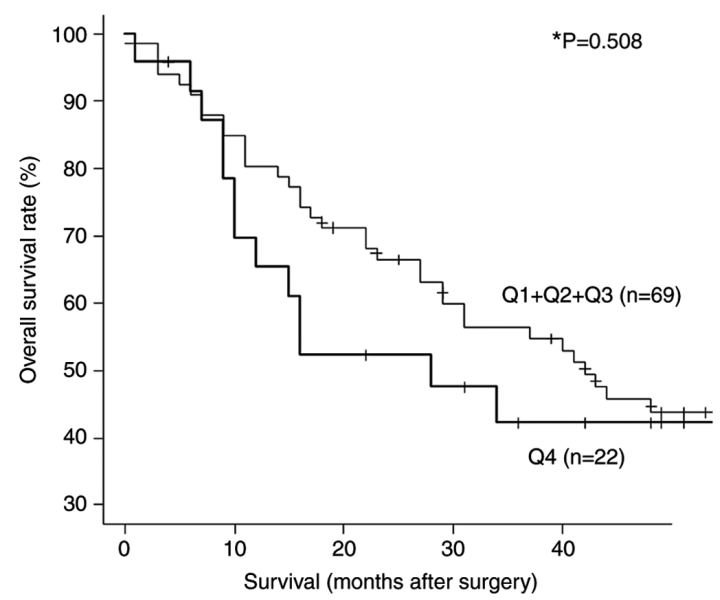

C Colorectal cancer
B

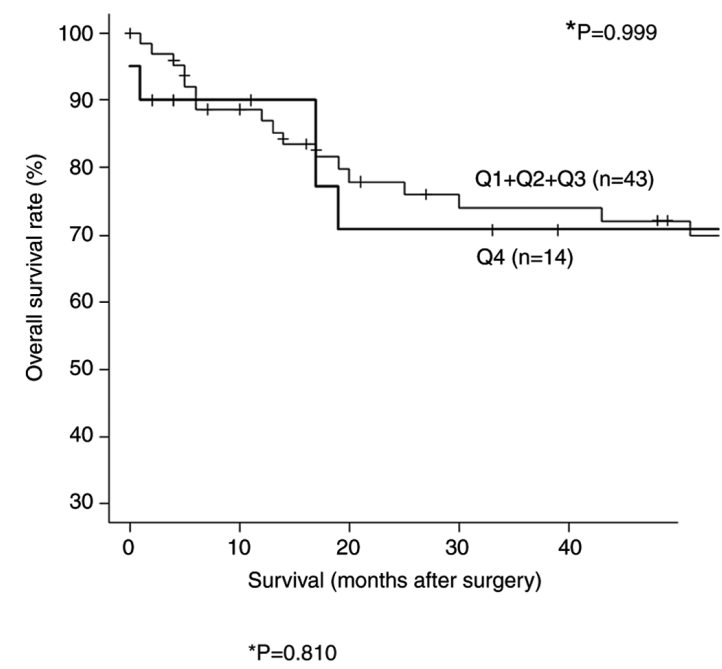

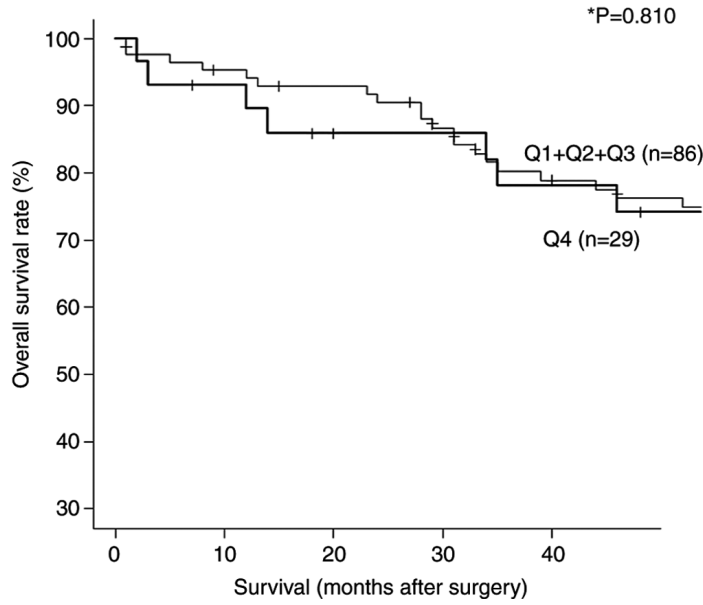

Figure 4. Comparison of patient overall survival according to serum striatin 4 antibody levels classified into two groups (Q1+Q2+Q3 vs. Q4) in (A) esophageal cancer, (B) gastric cancer and (C) colorectal cancer. The P-value at 48 months after surgery was 0.508 in patients with esophageal cancer. Q represents quartiles of serum STRN4 antibody levels. Q1 levels ranged from -827 to 184, Q2 ranged from 190 to 873, Q3 ranged from 1,106 to 2,746 and Q4 ranged from 2,876 to 39,727.

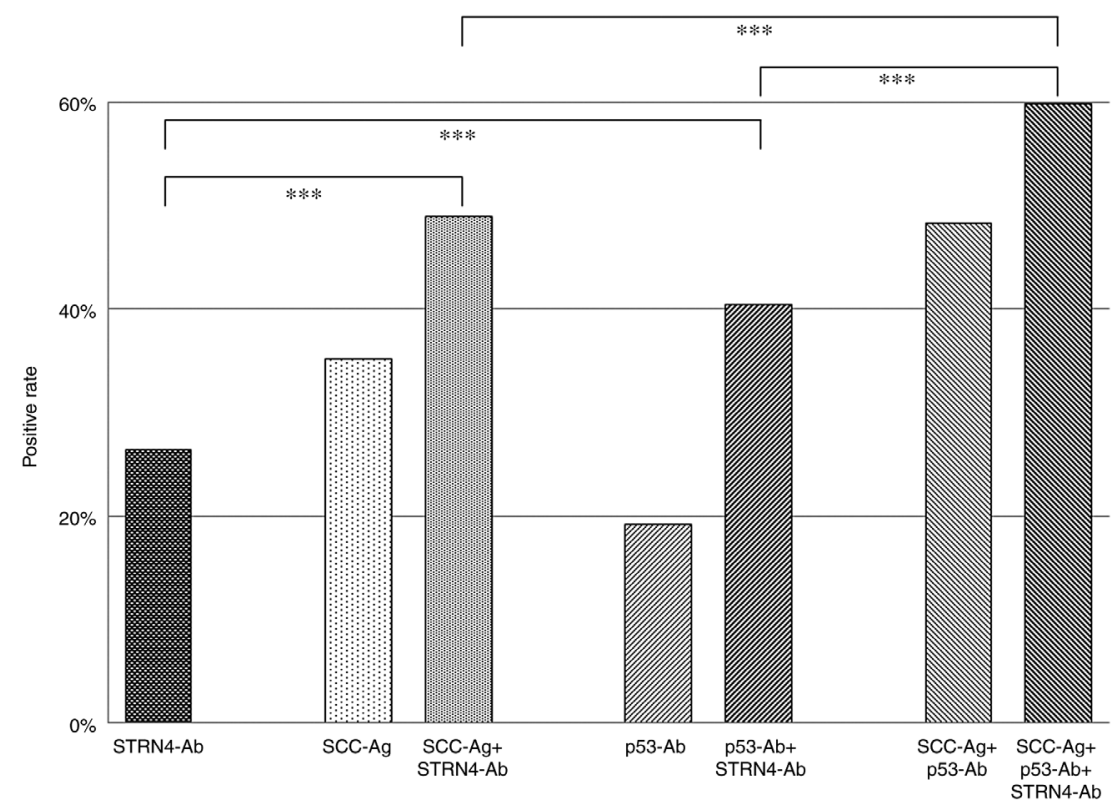

Figure 5. Positive rates of each or combined tumor markers for patients with esophageal cancer. The positive percentages of STRN4-Ab, SCC-Ag, SCC-Ag + STRN4-Ab, p53-Ab, p53-Ab + STRN4-Ab, SCC-Ag + p53-Ab, and SCC-Ag + p53-Ab + STRN4-Ab are presented. The cutoff level of STRN4-Ab was set to 2,746 (Q3 upper limit; 2,746) irrespective of the levels of SCC-Ag and p53-Ab. P-values were calculated with Fisher's exact test. ${ }^{* * *} \mathrm{P}<0.001$. The positive percentages have no variation. Q represents quartiles of serum STRN4 antibody levels. Q1 levels ranged from -827 to 184, 190 to 873 for Q2, 1,106 to 2,746 for Q3 and 2,876 to 39,727 for Q4. STRN4, striatin 4; Ab, antibody; SCC-Ag, squamous cell carcinoma antigen. 
reported that silencing of STRN4 suppresses the proliferation, migration, invasion, and anchorage-independent growth of several cancer cells (38). Wang et al suggested that miR-6165 inhibits the migration and invasion of gastric cancer cells by targeting STRN4 (39). Jiang et al indicated that Pokemon, through stimulation of STRN4 expression, promotes prostate tumor progression via a Pokemon/STRN4 axis (40). Wong et al reported that STRN4 was highly expressed in digestive-organ cancer cell lines and a lung cancer cell line (38). They also showed that STRN4 knockdown suppressed proliferation and metastasis of these cell lines. Consequently, STRN4 can facilitate carcinogenesis from the early stage to the advanced stage, which is consistent with our results that the s-STRN4-Ab marker was not correlated with the stage or TNM classification.

High s-STRN4-Ab levels indicated a poor postoperative prognosis for esophageal cancer, with similar results reported for liver cancer and ovarian cancer (41). High expression of STRN4 protein in these cancers indicates a poor prognosis especially in the early phase. For example, at 20 months after surgery, the survival rates for the Q1+Q2+Q3 and Q4 groups were 68 and 50\%, respectively. The 50\% survival periods for the Q1+Q2+Q3 and Q4 groups were 42 and 28 months, respectively. Thus, s-STRN4 levels might reflect a poor postoperative prognosis. Determining the risk of early postoperative death through the use of STRN4 antigen and antibody markers can be useful, because early treatment such as adjuvant therapy can improve the prognosis.

Antibody markers have differing characteristics from those of antigen markers. In the early stages of cancer, low-level tissue destruction and subsequent leakage of intracellular antigenic proteins lead to the emergence of autoantigens. Further repeated tissue destruction and leakage result in a remarkable increase in antibody levels, with antigen levels remaining constant. In the early stages, the sensitivity of the antibody markers is therefore much higher than that of antigen markers. In the advanced stages, tissue destruction becomes evident, and a large amount of antigen leaks out, which can result in partial absorption of the autoantibodies (29). Thus, the antigen markers might be suitable for diagnosing the late stages of cancer.

Although we have identified s-STRN4-Ab as a marker for digestive solid cancer, this is insufficient for achieving high sensitivity for diagnosing the early stage of cancers. Therefore we need to find additional useful biomarkers to improve the prognosis. s-STRN4-Ab levels were higher in patients with solid cancers than in healthy donors. The STRN4-Ab marker might reflect the poor postoperative prognosis of esophageal cancer.

\section{Acknowledgements}

The authors would like to thank Ms. Seiko Otsuka, Ms. Chiho Kusaka and Ms. Satoko Ishibashi (Department of Gastroenterological Surgery, Toho University School of Medicine) for preparing patient data.

\section{Funding}

This research was supported by the Japan Agency for Medical Research and Development, AMED and supported by a Grant-in-Aid for Scientific Research from the Ministry of Education, Culture, Sports, Science and Technology of Japan (grant nos. 16K10519, 16K10520 and 21K08695).

\section{Availability of data and materials}

The datasets used and/or analyzed during the current study are available from the corresponding author on reasonable request.

\section{Authors' contributions}

MI, TH and HS conceived the project and designed the experiments. YO, SY, TS, TN, MS, FS, KF, HT and KK performed acquired the data. YO, SY and NT collected clinicopathological information. MI, TH, MS and FS performed the experiments. MI and TH wrote the manuscript. All authors revised the manuscript. All authors have read and approved the manuscript. MI and TH confirm the authenticity of all the raw data.

\section{Ethics approval and consent to participate}

The present study was approved by the Institutional Ethics Committee of Toho University Graduate School of Medicine (Tokyo, Japan; approval no. A18103) as well as the review board of Chiba University Hospital. Serum was collected from patients who had provided written informed consent.

\section{Patient consent for publication}

Not applicable.

\section{Competing interests}

The authors declare that they have no competing interests.

\section{References}

1. Shimada H: Revisiting radiation therapy for esophageal cancer. Esophagus 17: 99, 2020.

2. Yang B, Liu Y, Li L, Deng H and Xian L: MicroRNA-200a promotes esophageal squamous cell carcinoma cell proliferation, migration and invasion through extensive target genes. Mol Med Rep 21: 2073-2084, 2020.

3. Fernandes E, Sores J, Cotton S, Peixoto A, Ferreira D, Freitas R, Reis CA, Santos LL and Ferreira JA: Esophageal, gastric and colorectal cancers: Looking beyond classical serological biomarkers towards glycoproteomics-assisted precision oncology. Theranostics 31: 4903-4928, 2020.

4. Shimada H, Takeda A, Arima M, Okazumi S, Matsubara H, Nabeya Y, Funami Y, Hayashi H, Gunji Y, Suzuki T, et al: Serum p53 antibody is a useful tumor marker in superficial esophageal squamous cell carcinoma. Cancer 89: 1677-1683, 2000.

5. Kochi R, Yajima S, Nanami T, Suzuki T, Oshima Y, Tokura N, Takatsuka J, Funahashi K, Tochigi $\mathrm{N}$ and Shimada $\mathrm{H}$ : Five-year postsurgical monitoring of serum p53 antibody for locally advanced esophageal squamous cell carcinoma. Clin J Gastroenterol 11: 278-281, 2018.

6. Suzuki T, Yajima S, Ishioka N, Nanami T, Oshima Y, Washizawa N, Funahashi K, Otsuka S, Nemoto T and Shimada H: Prognostic significance of high serum p53 antibody titers in patients with esophageal squamous cell carcinoma. Esophagus 15: 294-300, 2018.

7. Ito M, Yajima S, Suzuki T, Oshima Y, Nanami T, Sumazaki M, Shiratori F, Funahashi K, Tochigi N and Shimada H: High serum PD-L1 level is a poor prognostic biomarker in surgically treated esophageal cancer. Cancer Med 9: 1321-1327, 2020.

8. Ito M, Oshima Y, Yajima S, Suzuki T, Nanami T, Shiratori F, Funahashi $\mathrm{K}$ and Nemoto $\mathrm{T}$ and Shimada $\mathrm{H}$ : Is high serum programmed death ligand 1 level a risk factor for poor survival in patients with gastric cancer? Ann Gastroenterol Surg 2: 313-318, 2018. 
9. Ito M, Oshima Y, Yajima S, Suzuki T, Nanami T, Shiratori F, Funahashi K and Shimada H: Diagnostic impact of high serum midkine level in patients with gastric cancer. Ann Gastroenterol Surg 3: 195-201, 2019.

10. Oshima Y, Shimada H, Yajima S, Nanami T, Matsushita K, Nomura F, Kainuma O, Takiguchi N, Soda H, Ueda T, et al: NY-ESO-1 autoantibody as a tumor-specific biomarker for esophageal cancer: Screening in 1969 patients with various cancers. J Gastroenterol 51: 30-34, 2016.

11. Sahin U, Tureci O, Schmitt H, Cochlovius B, Johannes T, Schmits R, Stenner F, Luo G, Schobert I and Pfreundschuh M: Human neoplasms elicit multiple specific immune responses in the autologous host. Proc Natl Acad Sci USA 92: 11810-11813, 1995

12. Cancer Immunome Database: Available from: http://www2.licr org/Cancer ImmunomeDB/.

13. Nakashima K, Shimada H, Ochiai T, Kuboshima M, Kuroiwa N, Okazumi S, Matsubara H, Nomura F, Takiguchi $M$ and Hiwasa T: Serological identification of TROP2 by recombinant cDNA expression cloning using sera of patients with esophageal squamous cell carcinoma. Int J Cancer 112: 1029-1035, 2004.

14. Kuboshima M, Shimada H, Liu TL, Nakashima K, Nomura F, Takiguchi M, Hiwasa T and Ochiai T: Identification of a novel SEREX antigen, SLC2A1/GLUT1, in esophageal squamous cell carcinoma. Int J Oncol 28: 463-468, 2006.

15. Kuboshima M, Shimada H, Liu TL, Nomura F, Takiguchi M, Hiwasa $T$ and Ochiai T: Presence of serum tripartite motif-containing 21 antibodies in patients with esophageal squamous cell carcinoma. Cancer Sci 97: 380-386, 2006.

16. Shimada H, Kuboshima M, Shiratori T, Nabeya Y, Takeuchi A, Takagi H, Nomura F, Takiguchi M, Ochiai T and Hiwasa T: Serum anti-myomegalin antibodies in patients with esophageal squamous cell carcinoma. Int J Oncol 30: 97-103, 2007.

17. Shimada H, Shiratori T, Yasuraoka M, Kagaya A, Kuboshima M, Nomura F, Takiguchi M, Ochiai T, Matsubara H and Hiwasa T: Identification of Makorin 1 as a novel SEREX antigen of esophageal squamous cell carcinoma. BMC Cancer 9: 232, 2009

18. Kagaya A, Shimada H, Shiratori T, Kuboshima M, NakashimaFujita K, Yasuraoka M, Nishimori T, Kurei S, Hachiya T, Murakami A, et al: Identification of a novel SEREX antigen family, ECSA, in esophageal squamous cell carcinoma. Proteome Sci 9: 31, 2011.

19. Japan Esophageal Society: Japanese Classification of Esophageal Cancer, 11th Edition: Part I. Esophagus 14: 1-36, 2017.

20. Japanese Gastric Cancer Association: Japanese classification of gastric carcinoma: 3rd English edition Japanese Gastric Cancer Association. Gastric Cancer 14: 101-112, 2011.

21. Japanese Society for Cancer of the Colon and Rectum: Japanese Classification of Colorectal, Appendiceal, and Anal Carcinoma: The 3d English Edition [Secondary Publication]. J Anus Rectum Colon 3: 175-195, 2019

22. Shimada H, Kagaya A, Shiratori T, Nomura F, Takiguchi M, Matsubara $\mathrm{H}$ and Hiwasa T: Detection of anti-CUEC-23 antibodies in serum of patients with esophageal squamous cell carcinoma: A possible new serum marker for esophageal cancer. J Gastroenterol 44: 691-696, 2009.

23. Matsutani T, Hiwasa T, Takiguchi M, Oide T, Kunimatsu M, Saeki N and Iwadate Y: Autologous antibody to Src-homology 3-domain GRB2-like 1 specifically increases in the sera of patients with low-grade gliomas. J Exp Clin Cancer Res 31: 85 , 2012.

24. Machida T, Kubota M, Kobayashi E, Iwadate Y, Saeki N, Yamaura A, Nomura F, Takiguchi M and Hiwasa T: Identification of stroke-associated-antigens via screening of recombinant proteins from the human expression cDNA library (SEREX). J Transl Med 13: 71, 2015.

25. Yoshida Y, Wang H, Hiwasa T, Machida T, Kobayashi E, Mine S, Tomiyoshi G, Nakamura R, Shinmen N, Kuroda H, et al: Elevation of autoantibody level against PDCD11 in patients with transient ischemic attack. Oncotarget 9: 8836-8848, 2017.

26. Wang H, Zhang XM, Tomiyoshi G, Nakamura R, Shinmen N, Kuroda H, Kimura R, Mine S, Kamitsukasa I, Wada T, et al: Association of serum levels of antibodies against MMP1, CBX1, and CBX5 with transient ischemic attack and cerebral infarction. Oncotarget 9: 5600-5613, 2017

27. Kobayashi S, Hiwasa T, Ishige T, Rahmutulla B, Kano M, Hoshino T, Minamoto T, Shimada H, Nomura F, Matsubara $\mathrm{H}$ and Matsushita K: Anti-FIR $\Delta$ exon2, a splicing variant form of PUF60, autoantibody is detected in the sera of esophageal squamous cell carcinoma. Cancer Sci 110: 2004-2013, 2019.
28. Hiwasa T, Machida T, Zhang XM, Kimura R, Wang H, Iwase K, Ashino H, Taira A, Arita E, Mine S, et al: Elevated levels of autoantibodies against ATP2B4 and BMP-1 in sera of patients with atherosclerosis-related diseases. Immunome Res 11: 97, 2015.

29. Hiwasa T, Tomiyoshi G, Nakamura R, Shinmen N, Kuroda H, Kunimatsu M, Mine S, Machida T, Sato E, Takemoto M, et al: Serum SH3BP5-specific antibody level is a biomarker of atherosclerosis. Immunome Res 13: 132, 2017.

30. Shimada H, Ochiai T and Nomura F; Japan 53 Antibody Research Group: Titration of serum p53 antibodies in 1,085 patients with various types of malignant tumors: A multiinstitutional analysis by the Japan p53 Antibody Research Group. Cancer 97: 682-689, 2003.

31. Shimada H, Nabeya Y, Okazumi S, Matsubara H, Shiratori T, Gunji Y, Kobayashi S, Hayashi H and Ochiai T: Prediction of survival with squamous cell carcinoma antigen in patients with resectable esophageal squamous cell carcinoma. Surgery 133: 486-494, 2003.

32. Kanda Y: Investigation of the freely available easy-to-use software 'EZR' for medical statistics. Bone Marrow Transplant 48: 452-458, 2013

33. Castets F, Bartoli M, Barnier JV, Baillat G, Salin P, Moqrich A, Bourgeois JP, Denizot F, Rougon G, Calothy G and Monneron A: A novel calmodulin-binding protein, belonging to the WD-repeat family, is localized in dendrites of a subset of CNS neurons. J Cell Biol 134: 1051-1062, 1996.

34. Muro Y, Chan EK, Landberg G and Tan EM: A cell-cycle nuclear autoantigen containing WD-40 motifs expressed mainly in $\mathrm{S}$ and G2 phase cells. Biochem Biophys Res Commun 207: 1029-1037, 1995.

35. Castets F, Rakitina T, Gaillard S, Moqrich A, Mattei MG and Monneron A: Zinedin, SG2NA, and striatin are calmodulin-binding, WD repeat proteins principally expressed in the brain. J Biol Chem 275: 19970-19977, 2000.

36. Janssens V and Goris J: Protein phosphatase 2A: A highly regulated family of serine/threonine phosphatases implicated in cell growth and signalling. Biochem J 353: 417, 2001.

37. Hoof CV and Goris J: Phosphatases in apoptosis: To be or not to be, PP2A is in the heart of the question. Biochim Biophys Acta 1640: 97-104, 2003

38. Wong M, Hyodo T, Asano E, Funasaka K, Miyahara R, Hirooka Y, Goto H, Hamaguchi M and Senga T: Silencing of STRN4 suppresses the malignant characteristics of cancer cells. Cancer Sci 105: 1526-1532, 2014

39. Wang Z, Li Y, Cao J, Zhang W, Wang Q, Zhang Z, Gao Z, Ye Y, Jiang $K$ and Wang S: MicroRNA profile identifies miR-6165 could suppress gastric cancer migration and invasion by targeting STRN4. Onco Targets Ther 13: 1859-1869, 2020.

40. Jiang F, Zheng Q, Chang L, Li X, Wang X and Gu X: Pro-oncogene pokemon promotes prostate cancer progression by inducing STRN4 expression. J Cancer 10: 1833-1845, 2019.

41. The Human Protein Atlas:Available from: https://www. proteinatlas.org/ENSG00000090372-STRN4/pathology. 